\title{
The Significance of Chongqing Cross-Border E-Commerce in Promoting Regional Economic Development
}

\section{Li Zhen}

Department of Business Administration, Chongqing City Vocational College, Chongqing, China

\section{Email address:}

1848934829@qq.com

\section{To cite this article:}

Li Zhen. The Significance of Chongqing Cross-Border E-Commerce in Promoting Regional Economic Development. Science Innovation. Vol. 6, No. 4, 2018, pp. 240-244. doi: 10.11648/j.si.20180604.21

Received: June 25, 2018; Accepted: August 2, 2018; Published: August 3, 2018

\begin{abstract}
Under the guidance of the "One Belt and One Road" strategy, the international consumption structure has been upgraded year by year. The channels for Chinese consumers to experience cross-border products are more convenient and unimpeded. Due to the dual development opportunities, cross-border e-commerce has led to the transformation and upgrading of the traditional trade model, which has become a new trend of the transformation of China's foreign trade growth pattern. Cross-border e-commerce refers to the e-commerce model of goods transferring across regions through online trading, international payment, financial services, and offline international logistics delivery through the Internet and other e-commerce trading platforms. Cross-border e-commerce trade makes up for the shortcoming of traditional trade in cost and logistics and becomes a new driving force for China's foreign trade development. Since Chongqing became one of the first pilot cities of cross-border e-commerce in China, the number and transaction volume of cross-border e-commerce enterprises in the region have increased year by year. In recent years, cross-border e-commerce enterprises in the region have entered a golden period of development under the government's policy inclination. Taking Chongqing cross-border e-commerce as an example, this paper USES data statistics, literature analysis and field research methods to analyze the development status of cross-border e-commerce in Chongqing, analyzes regional, policy, logistics, enterprises and other advantages, and discusses the future development prospect of cross-border e-commerce and the driving force of regional economy. In order to help cross-border e-commerce enterprises in this region seize opportunities, actively participate in international market competition, and promote the rapid development of economy in Chongqing, the author puts forward some opinions on strengthening government policy support, strengthening enterprise brand management and school-enterprise cooperation in cultivating application-oriented e-commerce talents.
\end{abstract}

Keywords: Chongqing, Cross-Border E-commerce, Regional Economy

\section{重庆跨境电商对推动区域经济发展的意义}

\section{李真}

工商管理系, 重庆城市职业学院, 重庆, 中国

邮箱:

1848934829@qq.com

摘要：在“一带一路”战略引领下，国际消费结构逐年升级，中国消费群体体验跨境产品的渠道更为便捷、畅通，境外 消费者也同样感受着来自中国市场的高性价比产品, 双向推动进出口交易额逐年攀升。适逢双重发展机遇, 跨境电商 引导传统贸易模式转型升级, 已成为中国外贸增长方式转变的新趋势。跨境电商是指借助网络以及其它电商交易平台, 不同国家的交易者通过商品在线交易、国际支付、金融服务、线下国际物流送达等方式实现商品跨地区转移的电子商 务模式。跨境电商贸易弥补了传统贸易在成本、物流上的短板，成为拉动中国外贸发展的新动力。自重庆成为中国第 
一批跨境电子商务试点城市以来, 本区域内跨境电商企业数目及交易额逐年增长。近年来, 在政府政策倾斜下, 本区 域内跨境电商企业迎来发展黄金期。本文以重庆跨境电商为例, 运用数据统计、文献分析、实地调研的研究方法, 解 析重庆区域内跨境电商发展现状, 分析地域、政策、物流、企业等优势, 探讨今后跨境电商发展前景及对本区域经济 的推动力。提出在加大政府政策扶持力度、加强企业品牌管理及校企合作培养应用型电商人才等方面的见解，以帮助 本区域内跨境电商企业抓住机遇，积极参与国际市场竞争，推动重庆区域内经济的快速发展。

关键词：重庆, 跨境电商, 区域经济

\section{1. 引言}

随着“一带一路”战略实施, 国际消费结构逐年升级, 中国消费群体体验跨境产品的渠道更为便捷、畅通, 境外 消费者也同样感受着来自中国市场的高性价比产品, 双向 推动进出口交易额逐年上升。适逢双重发展机遇, 跨境电 商引导传统贸易模式转型升级, 已成为中国外贸增长方式 转变的新趋势。

跨境电商(Cross Border E-commerce)是指借助网络以 及其它电商交易平台，不同国家的交易者通过商品在线交 易、国际支付、金融服务、线下国际物流送达等方式实现 商品跨地区转移的电子商务模式。跨境电商贸易弥补了传 统贸易在成本、物流上的短板, 成为拉动中国外贸发展的 新动力。根据中国海关总署和中国国际电子商务中心统计 的数据显示， 2015 年中国跨境电商交易量为 5.4 万亿,增长 率为 $28.57 \%$, 占进出口总额的 $21.96 \%, 2016$ 年达到 6.5 万亿。 [9]在2018年《中国跨境进口零售电商行业发展研究报告》 (艾瑞咨询) 中显示，2017年中国跨境进口零售电商行业 市场规模约为 1113.4 亿元, 同比增长 $49.6 \%$ 。预计 2021 年 中国跨境电商的市场规模将突破3000亿元。

自重庆成为中国第一批跨境电子商务试点城市以来, 本区域内跨境电商企业数目及交易额逐年增长。[2]2018 年 2 月, 首届世界海关跨境电商大会在中国北京召开, 极 大推动了中国重庆跨境电商迅猛发展。本文以中国重庆跨 境电商为例, 解析重庆区域内跨境电商发展现状, 分析今 后发展趋势, 以帮助本区域内跨境电商企业抓住机遇, 积 极参与国际市场竞争, 推动重庆区域内经济的快速发展。

\section{2. 重庆跨境电商}

重庆在中国以山水之城著称, 有着悠久的人文历史和 自然风貌。其独特的地理位置和人文环境, 吸引了众多外 来人口及企业前来寻求发展机遇。2014年，50家跨境电商 企业在重庆注册。2015年, 重庆跨境电商进出口额较2014 年同比增长12倍, 近8亿元。[19]2016年前半年全市跨境电 商交易额达 110.8 亿元。其中 $\mathrm{B} 2 \mathrm{C}$ 业务进口 470 万单, 达 11.6 亿元, 同比增长约5倍; $\mathrm{B} 2 \mathrm{~B}$ 出口 50 亿元; 跨境电子商务 结算 49.2 亿元，同比增长76\%。[6]2016年重庆跨境电商相 关备案企业已经达 500 余家, 跨境电商交易额达 150.5 亿人 民币。[6]根据中国商务部发布的《关于商务部2017-2018 年度电子商务示范企业名单的公告》中显示：2017-2018 年度电子商务示范企业共238家, 其中重庆大龙网科技有 限公司等9家企业入选。截止2017年第四季度, 重庆的跨
境电子商务贸易额已超过中国上海位列第一, 跨境电商发 展取得了优异的成绩。

\section{1. 地域优势}

重庆作为中国长江经济带“㭷”字形大通道的重要连接 点、中心枢纽及陆上丝绸之路经济带和海上丝绸之路的战 略支点和经济腹地, 具有独具一格的地理环境优势, 起着 接通中国东西和南北的作用。依托地理优势，依靠“一带 一路战略”参与沿线 26 个发展中国家贸易, 重庆已将中国 内陆城市从事外贸的地理劣势转为优势, 涌现出一批具有 一定影响力的知名本地跨境电商企业和平台入驻, 推动重 庆外贸转型升级。在“中国十大最有前途城市”评选中, 重 庆凭借其较快的经济发展速度, 在众多城市中脱颖而出, 成为最有前途的城市之一; 重庆以其独有的鬼米力及活力, 促进了经济的增长, 推进了跨境电子商务的快速发展。[2]

洋展购董事长薛跃武表示, 洋展购选址两江新区, 对 重庆跨境电商发展前景绝对认可。重庆作为中国经济增速 最快的地区之一, 优质平价的进口商品有巨大的市场潜力, 而两江新区作为重庆唯一一个国家级新区, 拥有适合跨境 电商发展的绝佳环境。[11]

\section{2. 政策优势}

2012年8月，重庆获批成为跨境贸易电子商务服务试 点项目首批国家电子商务试点城市。2013年11月,重庆成 为中国仅有的具有跨境电子商务“一般进口”、“一般出口”、 “保税进口”、“保税出口”四种服务模式的全部业务实验城 市。2014年1月, 重庆全市跨境贸易电子商务服务试点累 计完成22.7万单，6636.72万元。同年6月，重庆市对外经 济委员会带头建立“重庆市跨境电商协会”。2015年，重庆 海关检验检疫局对跨境电子商务贸易采取了区别于传统 进出口贸易的优惠政策, 共验放跨境电子商务进口清单 332.7 万票, 货值达 7.86 亿元, 同比分别增长 14.9 倍和 12.1 倍, 首次实现有正式统计以来的高速增长。[5]2016年, 中 国国务院批准重庆为中国跨境电子商务综合试验区落户 城市。同年11月17日，“第二届中国·重庆国际跨境电商发 展峰会”的召开, 使重庆跨境电商得到重庆市政府高度的 支持，在政策的扶持下，近几年实现了交易额快速增长。

\section{3. 物流优势}

“渝新欧”国际铁路的开通, 将重庆与沿线的欧洲各国 联系更为紧密，成为欧洲及西方国家对外开放的前沿。“渝 新欧” 铁路以重庆为起点, 途经哈萨克斯坦、俄罗斯、白 俄罗斯、波兰, 抵达德国杜伊斯堡。单程运行时间 13 天, 
比海运省时近 1 个月, 运输成本大大降低。重庆西部物流 园总经理表示, 目前在 1000 趟中欧班列中, “渝新欧”通道 执行了 475班, 占到半壁江山。[15]“渝新欧”已成为中欧铁 运之间的主通道。“渝新欧”铁路的运行是中国境内跨境电 商和自由贸易区进行合作的重要通关途经, 是国际海运向 铁路联运的新发展，联运节约了资金和时间成本，极大地 促进了重庆跨境电商的高速发展。

2016年6月初, 重庆本土最大规模的跨境电商平台 —“西港全球购”荷兰“海外仓”正式启用, 这是重庆跨境电 商平台进口最大的“海外仓”, 为跨境电商境外供应链打造 迈上新台阶。2017年“双11”，渝中区的梅女士在凌晨 1 点 23 分下单了一盒奶粉, 当天下午 6 点 02 分, 包裹即签收。“双 11 ”当天, 重庆跨境电商订单实现 47 万单, 交易额达 1.2 亿元。 “双11”交易的火爆, 是重庆跨境电商快速发展的缩影。据 重庆海关统计, 2017年, 重庆跨境电商订单量达 1500 万单, 进出口贸易值达 33 亿元, 同比分别增长 $63 \% 、 60 \%$, 其中 订单量位居中国第六。[4]

\section{4. 跨境电商企业}

近年来, 根据数据显示, 重庆跨境电商、支付、物流 仓储三大类主体备案企业, 目前已突破 300 家, 其中包括 淘宝、京东等中国知名电商企业也在重庆设立了公司。作 为重庆跨境电商主阵地之一的重庆市渝中区, 跨境电商平 台已迎来爆发式增长。跨境贸易综合服务商重庆大龙木潭 公司上半年进出口额突破 8 亿美元; 渝欧跨境公司新开设 “宝妈时光”跨境母婴商品体验店 90 余家、总数近 500 家, 公 司上半年实现网上交易额 2.09 亿元、同比增长近12倍; 位 于两路寸滩保税港区的重庆保税商品展示交易中心, 已拥 有注册备案和开展业务的跨境电商企业共121家。另外, 西永综合保税区已有 100 家电商企业及平台签约入驻包括 蜜芽宝贝、网易考拉、唯品会等。[14]

2014年在重庆保税港区的积极推动下，完成了 $\mathrm{O} 2 \mathrm{O}$ “线上十线下”联动发展模式，搭建“爱购保税”网站实 现与交易中心实体店有效衔接。重庆商社(集团)有限公司 旗下的“世纪购”、重庆渝欧公司的“西港全球购”、重庆跨 境宝等跨境电商企业在重庆已取得良好业绩。2015年重庆 跨境电商的“本土状元”一渝欧公司跨境电商业务共实现 订单 27.4 万笔, 线上交易额 9855.75 万元, 位列重庆本土跨 境电商第一名。2018年6月, 中国物流企业顺丰“丰趣海淘” 旗下跨境电商平台“Wow哇噢”全球首家精选店落户重庆 解放碑商圈。

\section{3. 重庆跨境电商发展前景}

\section{1. 消费潜力大}

重庆是中国西南地区经济发展最为强劲的城市之一, 从消费者结构、年龄、收入来看, 都值得开拓。区域内中 青年消费群体具有极强的购买能力, 该群体的消费观念更 新较快、感知度高, 易于接受新鲜事物, 愿意尝试国际品 牌, 且有较强购买欲望。由此可见, 跨境电商通过“货品 真、价格低、购买易”的进口业务在重庆具有极大发展潜 力。
来自重庆海关统计数据显示, 2017年重庆网购保税进 口模式累计验放跨境电子商务进口包裹约 1500 万件, 货值 人民币 32.4 亿元，相较2016年同期分别增长了 $63 \% 、 60 \%$; 直购进口模式共计验放进口包裹约 5.7 万件, 货值 1172 万 元，相较 2016 年同期分别增长了 $27.5 \% 、 23.5 \%$ 。零售进口 商品总值靠前的商品主要为奶粉、婴儿纸尿裤、护肤品、 食品、卫生巾、沐浴露和洗发水等。[1]

\section{2. “渝新欧”与“一带一路”}

重庆逐步加强同“一带一路”沿线国家尤其是东盟的 合作, 完善平台通道, 以渝新欧铁路为桥梁, 整合沿线国 家和城市, 使其成为跨境电商的目的地和采购地。“渝新 欧”从重庆出发, 全程11179公里, 连接中国与德国亚欧两 大经济体, 串联丝绸之路经济带沿途各国, 加速重庆本土 商品在欧洲的流通。

2017年9月26日, 首趟“跨境电商中欧专列”抵达重庆, 这是跨境电商行业内首次以铁路专列形式完成进口物流 贸易。位于重庆两路寸滩保税港区的跨境电商企业网易考 拉海购相关负责人介绍: “与一般跨境电商货物走海运、 空运相比，货物搭载中欧班列（重庆），一趟只需花费 14 天, 比传统海运缩短了 30 天, 且运费仅有空运的 $1 / 5$, 货 运量却比空运大十几倍。”数据显示, 截至2018年1月底, 网易考拉海购通过中欧班列（重庆）已进口了超过100个 集装箱的电商货品, 货值近 1 亿元人民币。[4]同样, 重庆 丰趣电子商务有限公司也享受到了“中欧班列+跨境电商” 的红利。该公司从欧洲运输的产品大部分为奶粉、家居生 活用品和保健品等, 通过中欧班列（重庆）, 每罐奶粉的 运输成本控制在 0.3 欧元左右, 比空运成本下降了 0.9 欧元。 截止目前, 公司在西部物流园租赁了 1 万平方米的保税仓, 累计货值超过 6000 万元。

海关总署曾这样评价:中欧班列(重庆)是目前中欧班 列中开行数量最多、服务质量最好、国际认可度和影响力 最大的,已成为中欧班列的代表和重要品牌。[16]跨境电商 进口商品搭乘渝新欧列车不仅降低跨境电商物流成本, 也 使渝新欧铁路回程货物增加, 降低渝新欧铁路运营成本, 极大促进了重庆物流体系的发展。

\section{3. 国产品牌走向世界}

重庆依托地缘优势, 在技术加工、生产安装及农贸产 品的出口外销方面应坚持“品牌战略”。充分发挥本地长安 汽车、摩托车、机器人加工制造的竞争优势, 加大在泰国、 马来西亚、印度尼西亚等市场的投放力度, 在辐射能力强、 资源丰富的国家和地区进行制造业、资源开发等领域的投 资合作。在农贸产品方面, 重庆以其特殊的气候孕育出独 具中国味道的农产品及土特产。目前, 电商平台京东在中 国打造了 20 余个重点城市生鲜馆, 江津是重庆第二家京东 美食地图地方生鲜馆, 首期上线 5 大类 20 多个产品, 包括 羊儿山富硒土鸡蛋、石门晚熟柑橘、石蟆古法手工甘蔗红 糖、慈云富硒有机蔬菜、猫山富硒茶和朋驰火锅底料等。 以电商推动农村经济的发展, 践行新农村建设, 拉动乡镇 企业走向世界, 实现外贸双赢。 


\section{4. 跨境电商企业落户重庆}

重庆作为中国具有跨境电商服务四种模式全业务 (一 般进口、保税进口、一般出口和保税出口) 的试点城市, 区域政策优势明显。自设立跨境电子商务综合试验区以来, 吸引了一大批电商企业落户。

2014年10月, 重庆港腾供应链管理有限公司 (以下简 称重庆港腾）入驻重庆两路寸滩保税港区, 为菜鸟、世纪 购等近 20 个电商平台提供仓储服务。重庆港滕相关负责人 介绍, “刚入驻时, 每月的出单量在 1 万左右, 如今每月出 单量达到 30 万单, 年增长率超过 $100 \%$ 。“双 11 ”期间, 仅 菜鸟一家的订单量就是前一年的4倍多。2016年1月8日, 唯品会跨境电商西南运营总部项目正式落户重庆, 经过两 年的发展, 2017 年该仓库处理订单量已超过 185 万单, 同 比增长约 $480 \%$ 。截至2018年, 在重庆两路寸滩保税港区、 重庆西永综合保税区、重庆铁路保税物流中心 (B型) 和 重庆南彭公路保税物流中心（B型）, 在营跨境电商企业 达102家，其中包括天猫国际、网易考拉、唯品会、蜜芽、 重庆宝妈时光、丰趣海淘等全国性大型电商企业。[4]

\section{4. 对区域经济的推动}

\section{1. 跨境电商企业入驻, 活跃市场经济}

重庆在中国搭建政府主导的“零审批、零收费”跨境电 商公共服务平台，使企业、订单、支付、物流等信息“一 口接入”, 降低了企业成本, 吸引众多跨境电商入驻, 活 跃了区域内市场经济, 拉动了GDP的增长, 提高了消费市 场容量, 带给消费者优质产品的同时, 增加了本地税收。 根据重庆市商务委提供的数据显示, 2013-2017年间, 重 庆市电商交易额及普及率在数值上都有较大范围增长。

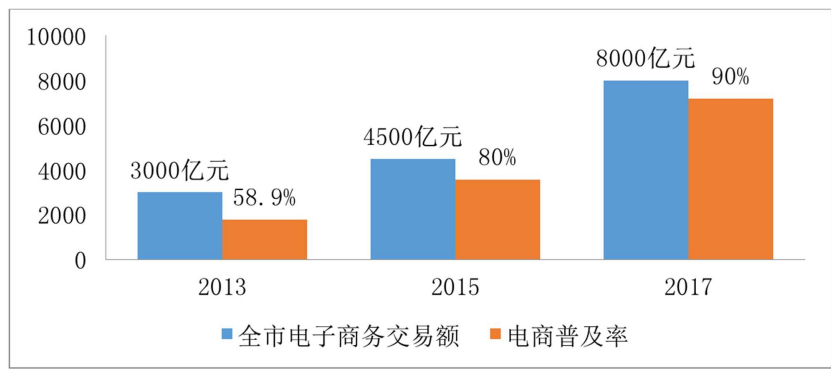

数据来源: 重庆市商务委（2018）电商交易统计数据

图1 2013-2017年重庆市电子商务交易额和电商普及率。

\section{2. 辐射国内外, 促进电商行业繁荣发展}

伴随“渝新欧”常态化, 重庆跨境电商成交额逐年增长, 吸引了大批跨境电商大鳄入驻, 有望成为内陆地区首个跨 境电商集散分拨中心, 其辐射中国内地的优势将进一步凸 显。通过整合内地资源, 开拓物流新模式, 从而节约时间、 空间成本，加快实现周边省市的经济发展。[15]

中新互联互通项目兰渝专列现已开通。同时，兰州发往 重庆至广西钦州港的货运专列也一同开行。兰渝铁路是中国 纵贯南北的大动脉, 是西部地区通往东盟的重要通道, 也是 中欧(重庆)国际铁路大通道的重要组成部分。兰渝专列的开
行, 连同不久前开通的“渝黔桂新”经广西钦州港, 海运至新 加坡等东盟各港口, 进而连通国际海运网络, 辐射全球。

\section{3. 促进就业, 缓解社会压力}

《中国电子商务发展报告2017》（以下简称报告）显 示, 电子商务直接从业人员和间接带动就业达 4250 万人, 同比增长 $13 \%$ 。而人力资源和社会保障部日前发布的

《2017年度人力资源和社会保障事业发展统计公报》指出, 截至2017年末，中国就业人员数量为 77640 万人。 [8]

在中国人民大学劳动人事学院课题组《阿里巴巴零售 电商平台就业吸纳与带动能力研究 (2017年度) 》报告中 显示: 2017年阿里巴巴零售生态创造就业机会总量达3681 万。其中平台产生了 1405 万个交易型就业机会, 这是在天 猫、淘宝、聚划算等平台上直接从事零售工作的就业者的 规模。零售业上游的研发设计、生产制造, 下游的快递物 流、售后服务等环节产生了2276万个带动型就业机会。电 商扩大了就业总人群, 让所有人获得公平的就业机会。例 如, 网店为女性、大学生、弱势群体创造了就业机会, 快 递业等扩大了农民工的就业, 成为传统就业的有益补充。

以重庆为例, 在九龙坡区留学生创业园, 有从海外归 来选择与朋友合开网店, 仅靠售卖文创产品, 在淘宝一年 销售额就达近百万元的海归学子; 在綦江区隆盛镇, 有返 乡创业的大学生在本村创建村淘服务站, 帮助周边农村采 购网上商品, 同时采购当地特色农产品进行网销, 一年收 入高达十几万元; 在江北一小区的菜鸟物流服务站, 有以 承包的方式做包裹寄存生意的大学生仅去年“双 11 ”期间, 收入已突破2万元。[20]

中国社科院世界经济与政治研究所全球治理室副主 任表示, 创造就业是新经济形式对中国就业领域做出的重 要贡献, 而有针对性地解决就业问题、改善民生是其背后 更值得肯定的特点。[20]新经济形式发展能够有针对性地 解决就业问题, 有效率地促进民生发展, 这些贡献在创造 就业岗位之外更加值得肯定。

\section{5. 结论}

\section{1. 加大政策扶持力度}

重庆拥有“水、陆、空”三个国家一类口岸、三个保税区 等独特的地理和物流优势, 市政府可凭借以上特色和相关的 政策和资金支持, 增加“正面清单”数量, 加大关注国际法律 对跨境电商的基本要求, 从中制定出符合中国市场对外贸易 的法律条文, 使跨境电商行业标准与世界接轨, 并增强监管 力度, 促进政策、法律法规、行业规范的有效实施, 以此推 进跨境电子商务的良性发展。进一步申报跨境电商B2B出口 试点, 鼓励并协助其跨境电商企业（如: 大龙网）在海外设 立“海外仓”, 全面构建跨境电商支撑服务体系, 为重庆跨境 电子商务的发展提供一个良性循环、有序增长的环境。

\section{2. 实施品牌战略}

参与跨境电商的企业需有自主品牌。在产品上需持续 创新, 走品牌战略路线。一方面打造技术先进、实力雄厚 的大企业主动参与国际竞争。着力打造国际品牌, 积极参 
与国际合作。对中小企业进行“品牌意识”的引导, 扩大品 牌宣传培训, 对国际经济形势进行宣讲, 鼓励创立自主品 牌, 引导参与国际竞争。目前, 汽摩配件及计算机通信及 其电子设备的出口是重庆跨境电商的主要交易品种之一, 也为重庆跨境电商企业提供了丰富的交易对象。汽摩配件 等重庆造产品质量的提升及品牌的创立有助于帮助重庆跨 境电商企业开拓海外市场。另一方面, 鼓励具有一定品牌 优势的传统企业自建电商平台。通过企业网站、在线直播、 社交网推广等新模式, 拓展国际市场, 推动传统企业转型 升级。在北京召开的第十五届中国国际农产品交易会上, 包括重庆“荣昌猪”“涪陵榨菜”“奉节脐橙”在内的全国100个 品牌被组委会授予“2017中国百强农产品区域公用品牌”称 号。获选品牌均获得农产品地理标志认证、登记或注册, 涵盖粮食、油料、蔬菜、果品、肉类、淡水产品、海水产 品、中药材等多类重要农产品。品牌认证入驻电商平台及 自媒体推广平台有助于传统农贸企业打入国际市场。

\section{3. 电商人才分类培养}

随着中国跨境电商贸易的逐年增长, 企业逐步加大对 人才的需求量, 而人才资源短缺已成为制约跨境电商行业 发展的瓶颈。各级院校应与企业联合培养, 使人才符合从 业要求。

重庆本地大中专院校开设有电子商务专业, 根据人才 培养规格不同, 对企业的需求也不同。对于本科类院校, 学生英语基础较好, 能够协助进行客户沟通交流、传达信 息、交易确认、商品发货等一系列流程, 可作为电商行业 中高端人才培养; 大专院校的学生在平台操作维护、线下 物流控制及产品甄选上有自己的优势, 可重点培养。

除学生自身素质外, 引入企业项目, 让在校生进一步 感受操作流程、行业规范及企业文化, 以便毕业即可就业。 重庆师范大学涉外商贸学院及重庆城市职业学院电商专 业引进阿里巴巴“百城千校, 百万英才”项目, 校企联合培养 跨境电商人才, 推进所学专业与企业需求相结合, 填补本 地电商人才缺口，促进毕业生充分就业。

\section{致谢}

本文为重庆城市职业学院2017年校级人文社科重点 项目《“一带一路”背景下重庆跨境电商对推动区域经济发 展研究》 (17XJRW002) 的阶段性成果之一。感谢学校所 提供的项目配套资金及相关硬件设施支持及系部为本次 工作提供相关企业考察调研活动（校企合作企业（阿里巴 巴)、重庆大龙网科技有限公司、龙工场跨境电商产业园、 重庆黔江濯水古镇 $\mathrm{O} 2 \mathrm{O}$ 体验店) 为协助完成本项目提供了 有力支持。感谢参与本项目的前期主研人员对论文撰写提 供的前期数据资料及文献资料的收集、整理。感谢本次大 会为项目研究提供了与国内外相关政府、企业、事业单位 沟通、交流的平台。

\section{参考文献}

[1] 韩政.重庆人海淘最爱买啥?奶粉、纸尿裤、护肤品[N].重庆 商报.2018-2-10(008):1-2.

[2] 叶淑芸.浅析重庆跨境电商的发展[].现代商业.2017,(15):36-37.

[3] 卢灵芝,刘开华.重庆中小企业跨境电商发展的问题及对策 研究[J].市场周刊.2018,(01):88-89.

[4] 杨艺. 重庆跨境电商驶上“快车道”2017年订单量增长六成 [N].重庆日报.2018-2-10(002):1-2.

[5] 张灿. 重庆跨境电商发展现状分析及对策建议[J].重庆科技 学院学报(社会科学版).2016,(05):57-58.

[6] 孙桂娥,乔丰娟,袁林.重庆跨境电商发展现状及对策建议[J]. 电子商务.2017,(04):27-28.

[7] 渝欧.重庆跨境电商平台“西港全球购”首次走出国门,渝企 在荷兰设立“海外仓”[N].国际商报.2016-4-28(C02):1.

[8] 韦斐琼.“一带一路”战略红利下跨境电商发展对策[J].中国 流通经济.2017,(03):62-64.

[9] 朱启松,朱慧婷““互联网+”背景下跨境电商发展的SWOT分析以重庆为例[].四川理工学院学报(社会科学版).2016,(19):74-78.

[10] 涂红雨,张超.“互联网+”护航重庆跨境电商健康发展 $[\mathrm{N}]$.中 国国门时报.2016-12-26(002):1.

[11］赵宇飞.重庆跨境电商迅猛发展[N].国际商报.2016-1-6 (A08):1.

[12] 秦娟.中国(重庆)跨境电子商务综合试验区的机遇与挑战[J]. 时代金融.2017,(04):84-85.

[13] 李国. 跨境电商促进传统商贸转型升级 $[N]$. 工人日 报.2016-11-2(007):1-3.

[14] 王彩艳.江北区:电商企业扎堆发展,跨境联合实现成果共享 [N].重庆日报.2015-11-13(003):1-2.

[15] 高江虹.跨境电商首搭“渝新欧”掘金重庆一带一路 $[\mathrm{N}] .21$ 世 纪经济报道.2015-6-29(011):1-2.

[16] 杨骏.创新大通道建设重庆由内陆腹地变为开放前沿 $[\mathrm{N}]$.重 庆日报.2017-10-2(004):1-2.

[17] 胡娟.高职院校跨境电商校企合作人才培养研究综述 [J].江 苏经贸职业技术学院学报.2018,(07):62-64.

[18] 徐露露. 跨境电商人才培养研究综述 []. 对外经 贸.2018,(04):108-109.

[19] 陈钧.重庆跨境电商去年交易额近8亿同比增长12倍 $[\mathrm{N}]$.重 庆日报.2016-03-21(001):1-2.

[20] 张宇. 重庆匠人开网店月入 3 万电商新就业形态受热捧 $[\mathrm{N}]$. 重庆商报.2018-04-05(001):1-2. 